\title{
The study on the emission list of fine particulate matter, which are discharged from the traffic flow source in Guilin
}

\author{
Huihong Luo ${ }^{a}$,Lei Liao ${ }^{b}$ \\ (College of Environmental Science and Engineering, Guilin University of Technology ,Guilin \\ 541004 ,Republic of China)

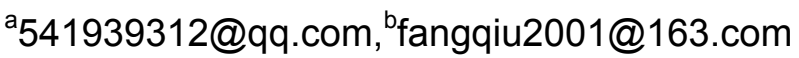

Keywords: traffic flow resource, emission factors, fine particulate matter, Guilin

\begin{abstract}
According to the researches of Guilin's vehicle population from 2011 to 2013, the emission factors were determined after referenced literatures from home and abroad. The researcher calculated Guilin's annual emission of fine particulate matter from traffic flow was 248.14 tons. Among these different vehicles, middle-heavy truck tops first as the main pollution resource with 146.80 tons of pollution emission each year. The second pollution resource is motorcycle with 48.71 tons pollution emission each year. Compared with other pollution resources, traffic flow resource is the main pollution resource for atmospheric fine particulate matter. Because the road construction cannot reach the rapid construction of the whole city, there are many traffic congestions at present. Therefore, the waiting time of vehicles increases and the oil consumption of each vehicle also increases each mile. Moreover, the pollution emission also increases each mile, which is also the main cause for the atmospheric pollution.
\end{abstract}

\section{Introduction}

In recent ten years, the vehicle population in our country is increasing at a rapid growth of 15 percent each year. At present, the vehicle exhaust is the main pollution in the cities around our country. The pollution emission from the vehicles is becoming one of the main resources of urban atmospheric pollution. The relative researches are the hot-spots for the scientists at home and abroad $^{[1]}$.

At present, Guilin's atmospheric pollution cannot be ignored. From the year of 2010, the atmospheric pollution in Guilin was beyond levellIIand there is a tendency that the days with atmospheric pollution increases. According to the AAQS (ambient air quality standard) (GB3095-1996), the satisfaction rate of air in 2013 was 91.5 percent. The primary atmospheric pollution in Guilin is inhalable fine particulate matter- $\mathrm{PM}_{2.5}$.

Through the investigation of Guilin's vehicle population from 2011 to 2013, based on the basic calculation formula, which is recommended by the Technical Guidelines of Emission List of PM 2.5 , the researcher sets up the emission list of Guilin's $\mathrm{PM}_{2.5}$. from the traffic flow resource.

\section{The research methods}

\subsection{The research methods of traffic flow resource}

\subsubsection{The calculation formula of the emission of particulate matter}

Firstly, according to the fuel consumption (the second classification of the sources), various kinds of burning (the third classification of the sources) and the percentage of control techniques of particulate matter (the fourth classification of the sources), the research gets the fourth emission level. Based on the Technical Guidelines of Emission List of $\mathrm{PM}_{2.5}$, the researcher identifies the production index of $\mathrm{PM}_{2.5}$ At last, the researcher calculates the emission of $\mathrm{PM}_{10}$ and $\mathrm{PM}_{2.5}{ }^{[2]}$. The calculation formula is:

$$
E=A \times E F(1-\eta)
$$

$\mathrm{E}$ stands for the emission of $\mathrm{PM}_{2.5}, \mathrm{t} / \mathrm{a}$. A stands for the oil consumption, $\mathrm{t} / \mathrm{a}$. EF stands for the emission index, $\mathrm{g} / \mathrm{kg}$. $\eta$ stands for the removal efficiency for $\mathrm{PM}_{2.5}$ by pollution control techniques, $\%$. 
The activity level of traffic flow resource-A will be calculated by the formula (2). The calculation formula is:

$A=V P \times V K T \times F E$

VP stands for the vehicle population. VKT stands for the vehicle's trip distance. FE stands for the oil consumption each mile.

\subsubsection{The identification of emission index in research area}

Emission factors have a significant influence on the accurate calculation of pollutants from the emission sources. Referenced by the data in AP-42 $2^{[3]}$, which is recommended by Environmental Protection Agency, and combined with recently researches by scholars of zhang J, Chen Y and Lei, $\mathrm{Y}^{[4-11]}$, the researcher confirms Guilin's emission index of $\mathrm{PM}_{2.5}$ from the traffic flow resource, which is demonstrated in table 1.

Tab.1 Guilin's emission index of PM 2.5 from the traffic flow resource

\begin{tabular}{|c|c|c|c|}
\hline Different types of vehicles & $\begin{array}{c}\text { Annual mileage } \\
{[\mathrm{km}]}\end{array}$ & $\begin{array}{c}\text { Production index of } \\
\text { gasoline }[\mathrm{g} / \mathrm{kg}]\end{array}$ & $\begin{array}{c}\text { Production index of } \\
\text { diesel }[\mathrm{g} / \mathrm{kg}]\end{array}$ \\
\hline $\begin{array}{l}\text { Mini-model Passenger } \\
\text { Accommodation Vehicle }\end{array}$ & $15000^{[12]}$ & 0.01 & -- \\
\hline $\begin{array}{l}\text { Small-Model Passenger } \\
\text { Accommodation Vehicle }\end{array}$ & $20000^{[12]}$ & 0.02 & -- \\
\hline $\begin{array}{l}\text { Middle-model Passenger } \\
\text { Accommodation Vehicle }\end{array}$ & $28000^{[12]}$ & 0.06 & 1.38 \\
\hline $\begin{array}{l}\text { Great-model Passenger } \\
\text { Accommodation Vehicle }\end{array}$ & $30000^{[12]}$ & 0.05 & 1.46 \\
\hline Mini-truck & $15000^{[12]}$ & 0.02 & -- \\
\hline Light-truck & $20000^{[12]}$ & 0.10 & -- \\
\hline Middle-heavy truck & $28000^{[12]}$ & -- & 1.36 \\
\hline Heavy-truck & $30000^{[12]}$ & -- & 3.47 \\
\hline Motorcycle & $10000^{[12]}$ & 4.65 & -- \\
\hline
\end{tabular}

Vehicles' emission level of III was executed from 2007 in our country. Therefore, the researcher takes this standard as Guilin's emission index of traffic flow resource.

\section{The result and discussion}

\subsection{The emission list of Guilin's traffic flow resource}

According to the vehicles population, annual vehicle's trip distance and the emission factors of various types of vehicles, the researcher sets up Guilin's emission list of traffic flow resource according to the formula (2), which is demonstrated in tab.2:

Tab.2 Guilin's emission list of traffic flow resource

$[\mathrm{t} / \mathrm{a}]$

\begin{tabular}{ccccccc}
\hline $\begin{array}{c}\text { Different } \\
\text { types of } \\
\text { vehicles }\end{array}$ & Time & $\begin{array}{c}\text { Emission } \\
\text { quantity of } \\
\text { gasoline } \\
\text { vehicles }\end{array}$ & $\begin{array}{c}\text { Emission } \\
\text { quantity of diesel }\end{array}$ & $\begin{array}{c}\text { Total } \\
\text { emission } \\
\text { quantity }\end{array}$ & $\begin{array}{c}\text { Annual } \\
\text { emission } \\
\text { quantity }\end{array}$ & $\begin{array}{c}\text { Contribu } \\
\text { tion rate }\end{array}$ \\
\hline Heavy-truck & 2011 & -- & 118.03 & 118.03 & & \\
& 2012 & -- & 143.38 & 143.38 & 146.80 & 59.16 \\
& 2013 & -- & 179.00 & 179.00 & & \\
Motorcycles & 2011 & 39.16 & -- & 39.16 & & \\
& 2012 & 47.58 & -- & 47.58 & 48.71 & 19.63 \\
Great-model & 2013 & 59.39 & -- & 59.39 & & \\
Passenger & 2011 & 0.06 & 17.32 & 17.37 & & \\
Accommodat & 2012 & 0.07 & 21.04 & 21.11 & 21.61 & 8.71 \\
ion Vehicle & 2013 & 0.09 & 26.27 & 26.35 & & \\
Middle-heavy & 2011 & -- & 13.79 & 13.79 & 17.15 & 6.91 \\
truck & 2012 & -- & 16.76 & 16.76 & 176 \\
\hline
\end{tabular}




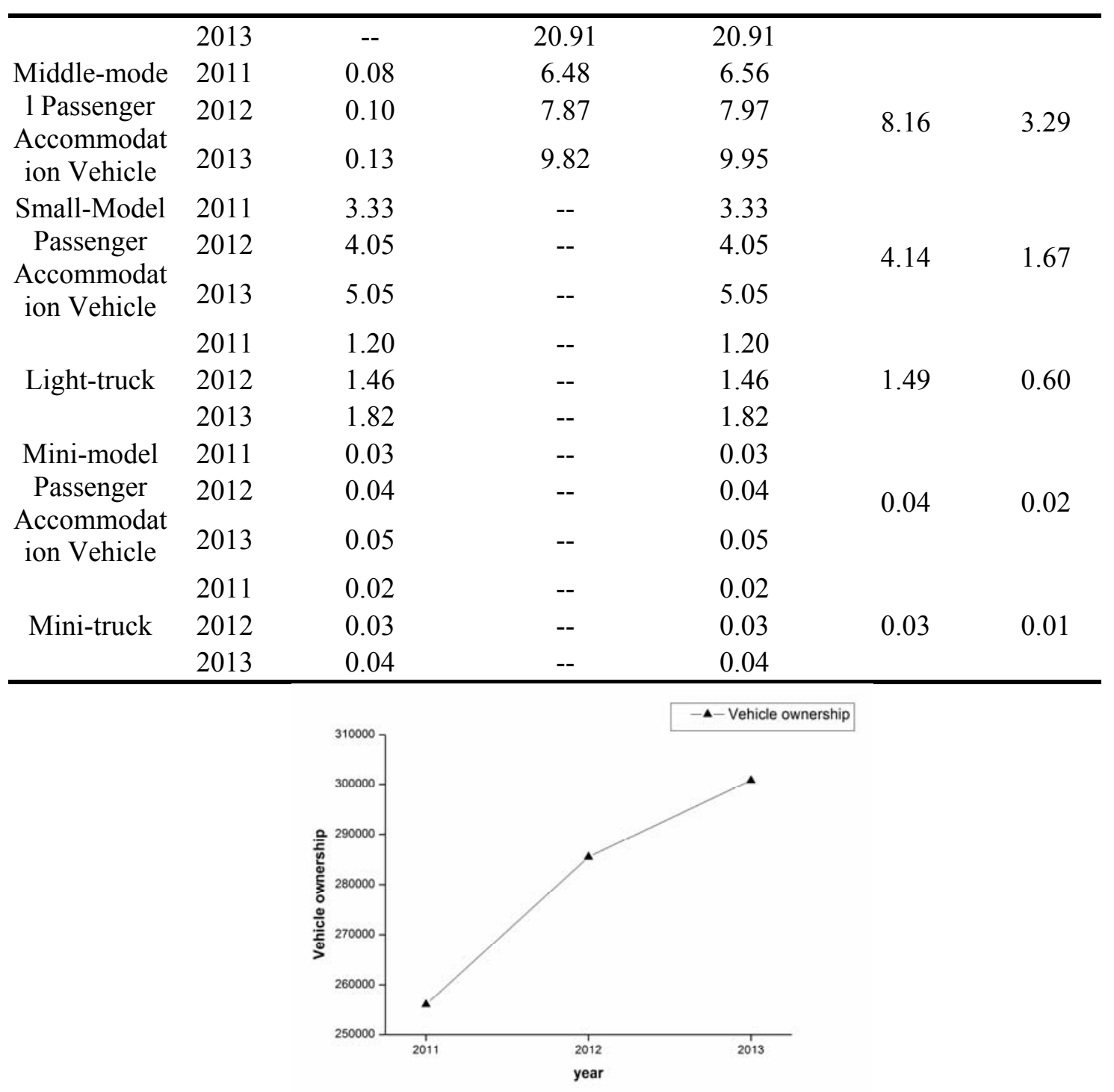

Fig.1Vehicle ownership of 2011-2013 in Guilin

According to tab.2, fig.1because Guilin's whole vehicle population increases, there is a tendency that the emission quantity of PM 2.5 from traffic flow resource in the year from 2011 to 2013 also increases. The annual emission quantity is 248.14 tons, but PM 2.5's emission quantity of various vehicles remains. Among these different traffic vehicles, middle-heavy truck is the main pollution resource for the atmospheric fine particulate matter with 146.80 tons of annual emission and 59.16 percent contribution rate. Owing to the long annual mileages and big oil consumption of each mile, as well as large fine particulate matter from the diesel consumption, the fine particulate matter from the diesel-fueled vehicles has become the primary pollution in Guilin. The annual emission contribution rate is 57.76 percent. The second pollution resource is motorcycle with 48.71 tons pollution emission each year, because motorcycle is one of the main transportation means for Guilin's residents and its vehicle population is large. However, the largest vehicle population is minibus. Because of the short annual mileages and small oil consumption of each mile, as well as little fine particulate matter from the oil consumption, PM 2.5's emission quantity ranks sixth in all types of vehicles.

\subsection{The comparison of traffic flow resource and other pollution resources}

The researcher makes a comparison and analysis of industrial pollution resource, catering pollution resource, domestic pollution resource, road dust resource and traffic flow resource, which is demonstrated in tab. 3 
Tab.3 Guilin's emission list of fine particulate matter [t/a]

\begin{tabular}{cccc}
\hline $\begin{array}{c}\text { Different types of pollution } \\
\text { resources }\end{array}$ & \multicolumn{3}{c}{ Emission quantity Contribution rate Where the data is from } \\
\hline Traffic flow resource & 248.14 & 17.47 & This research \\
Domestic pollution resource & 752.75 & 53.00 & \\
Industrial pollution resource & 207.20 & 14.59 & Guilin's Environment \\
Road dust resource & 187.50 & 13.2 & Monitoring Station \\
Catering pollution resource & 24.66 & 1.74 & \\
\hline
\end{tabular}

According to tab.3, the traffic flow resource tops second in Guilin's emission list of fine particulate matter with 17.47 percent of annual contribution rate. Because Guilin's road construction cannot reach the rapid construction of the whole city, there are many traffic congestions. Therefore, the waiting time of vehicles increases and the oil consumption of each vehicle also increases each mile and the pollutants also increases. Besides, there are nearly 200 standard yellow cars in Guilin. Each standard yellow car's emission equals to the emission of 20 standard green cars ${ }^{[1]}$.

\section{Conclusion}

We can draw the conclusion that Guilin's whole vehicle population increase and there is a tendency that the emission quantity of PM 2.5 from traffic flow resource from 2011 to 2013 also increases. The annual emission quantity is 248.14 tons. Among these various types of vehicles, middle-heavy truck is the main pollution resource for the atmospheric fine particulate matter with 146.80 tons of annual emission. Compared with other pollution resources in Guilin, traffic flow resource is one of the main pollution resources of fine particulate matter.

\section{Acknowledgments}

This study was supported by the National Natural Science Foundation of China (51468011).

\section{References}

[1]Guo Y H,Wang Z F,Kang H,et al.Acta Scientiae Circumstantiae, 34( 5) : 1109-1117.(2014)(in Chinese)

[2]GB 3095-2012,Ambient Air Quality Standards.(in Chinese)

[3]USEPA.Compilation of air pollutant emission factors (AP-42) Volume 1: point and area sources[R]. Research Triangle Park, NC.(1996)

[4] Zhang J, Smith K R, Ma Y, et al.. Atmospheric Environment, 34(26): 4537-4549.(2000 )

[5]Chen Y, Sheng G, Bi X, et al.Environmental Science \& Technology, 39(6): 1861-1867.(2005)

[4]ChenY,Zhi G,Feng Y,et al. Geophysical Research Letters, 33(20).(2006)

[5]Zhi G, Chen Y, Feng Y, et al. Environmental science \& technology, 42(9): 3310-3315.(2008)

[6]Shen G, Yang Y, Wang W, et al. Environmental science \& technology, 44(18): 7157-7162. (2010)

[7]Zhang Y, Schauer J J, Zhang Y, et al.Environmental science \& technology, 42(14): 5068-5073.(2 008)

[8]Ge S, Xu X, Chow J C, et al. Environmental science \& technology, 38(17): 4612-4618. (2004)

[9]Lei, Y., et al. Atmos. Chem. Phys., 11, 931-954.(2011)

[10]Zhao, Y., et al. Atmos. Environ., 42, 8442-8452.(2008)

[11]Zhao, Y., et al. Atmos. Environ., 44, 1515-1523.(2010) 
[12]Tang D G, Zhang Y H, L i J L, et al.Program No 96- 910- 03- 01. Be ijing: Ch in ese Acad emy ofEnvironm en ta $1 \mathrm{~S}$ cien ce, Pek ing $\mathrm{U}$ nivers ity, The Ins titu te of E nvironm ental Science inGu angzhou, 1-61.(1999).(in Chinese) 